\title{
THE ROLE OF SELECTED DIETARY AND LIFESTYLE FACTORS IN THE OCCURRENCE OF SYMPTOMS IN CHILDREN WITH FUNCTIONAL ABDOMINAL PAIN - A PILOT STUDY
}

\author{
Katarzyna M. Boradyn ${ }^{1 凶}$, Katarzyna E. Przybyłowicz ${ }^{1}$, Elżbieta Jarocka-Cyrta² \\ ${ }^{1}$ Department of Human Nutrition, University of Warmia and Mazury in Olsztyn \\ Stoneczna 45F, 10-718 Olsztyn, Poland \\ ${ }^{2}$ Department of Pediatrics, Gastroenterology and Nutrition, University of Warmia and Mazury in Olsztyn \\ Żołnierska 18A, 10-561 Olsztyn, Poland
}

\begin{abstract}
Background. Functional abdominal pain disorders (FAPDs) are a common health problem in the pediatric population. Research suggests that several environmental modifiable factors, such as physical activity, growth status and dietary habits, may determine the symptoms of the disease. The aim of this pilot study was to assess whether the frequency and severity of gastrointestinal symptoms are associated with dietary intake, physical activity level and BMI in children with functional abdominal pain (FAP).

Materials and methods. The study enrolled 25 children (5-11 years old) with diagnosed FAP. Dietary intake data were collected using a 7-day food diary. Patients were asked about physical activity at school and during their free time. Participants collected information about gastrointestinal symptoms over a 2-week period. The frequencies of abdominal pain and stools were recorded as number of events per day; the severity of abdominal pain was assessed using the Wong-Baker FACES Pain Rating Scale, and stool consistency based on the Bristol Stool Form Scale. Differences between groups were verified with the Kruskal-Wallis test. Results. In the group of children with insufficient intake of fiber, abdominal pain intensity was significantly higher (median: 1.75 points/day, IQR: 1.18-2.32) than among participants with adequate intake (median: 0.29 points/day, IQR: $0.08-0.57 ; p=0.006$ ). Stool frequency was significantly lower in children who reported moderate physical activity in their free time (median: 0.86 times/day, IQR: $0.64-1.14$ ) than in children with high free time physical activity (median: 1.36 times/day, IQR: $1.29-1.50 ; p=0.031$ ). There was no significant association between other lifestyle factors and gastrointestinal symptoms.

Conclusion. Our results suggest that simple recommendations relative to modifiable lifestyle factors, such as diet or physical activity, may reduce abdominal pain intensity and improve stool frequency in children with FAP.
\end{abstract}

Keywords: pediatric, dietary intake, physical activity, Body Mass Index, functional abdominal pain, lifestyle factors

Funding Source Declaration: This study was funded in full by the National Science Centre, Poland, grant number 2015/17/N/ NZ5/02596. 


\section{INTRODUCTION}

Abdominal pain is a common symptom in the pediatric population. The majority of children with chronic abdominal pain have symptoms that fall under the criteria for functional abdominal pain disorders (FAPDs), defined as Rome criteria (Gupta et al., 2018). Based on the symptoms, FAPDs can be further classified as functional abdominal pain (FAP), irritable bowel syndrome (IBS), functional dyspepsia (FD) and abdominal migraine (AM) (Nurko, 2009). The pathophysiology of FAPDs is multifactorial and involves a complex interaction between visceral hypersensitivity, dysmotility, dysbiosis of the GI tract, alteration in the brain-gut axis and psychosocial factors (Chumpitazi and Shulman, 2016; Hyams et al., 2016).

Classifying functional abdominal pain into subtypes can be helpful in directing treatment. Functional abdominal pain - FAP is defined as abdominal pain occurring at least 4 times a month, not connected to physiologic events, and that cannot be fully explained by another medical condition (Rasquin et al., 2006). It has a chronic course and can impact school performance and social relationships. Patients with FAP often report impaired quality of life due to gastrointestinal symptoms (Brusaferro et al., 2018; Nurko, 2009; Rajindrajith et al., 2018). Moreover, the disease generates considerable healthcare costs (Nurko, 2009; Rajindrajith et al., 2018). To date, no medication-based treatment has been proven to be effective in children with FAP (Landry et al., 2015; Gupta et al., 2018). Most studies were conducted in patients with IBS or in mixed groups with various FAPDs (Brusaferro et al., 2018; Gupta et al., 2018; Rajindrajith et al., 2018) and to the best of our knowledge, there are no studies specifically examining the associations between various lifestyle factors and symptoms of FAP in children, even though the prevalence of FAP is similar to that of IBS.

Research suggests that several factors, including modifiable environmental factors such as dietary intake, eating habits, Body Mass Index (BMI) and physical activity, contribute to the pathophysiology of FAPDs in children (Gupta et al., 2018). The growing number of children with FAPDs may be due, among other things, to changes in children's lifestyles, including lower physical activity levels, increased stress and consumption of sweets, sweetened beverages and junk food (Gupta et al., 2018; Landry et al., 2015). The association between physical activity, BMI, dietary habits and occurrence of gastrointestinal symptoms has been assessed in recent years, mainly in children with IBS and FD (Chumpitazi, 2018; Landry et al., 2015). However, there have been only a few studies conducted in children with FAP and knowledge of the impact of these factors is limited. It is also still unclear whether the fact that the disease itself prevents children from being physically active contributes to unhealthy dietary habits, or whether these behaviors have a causal effect on worsening gastrointestinal symptoms.

The aim of this pilot study was to determine whether the frequency and severity of gastrointestinal symptoms are associated with dietary intake, physical activity level and/or BMI in a homogenous group of FAPD children specifically diagnosed with FAP.

\section{MATERIALS AND METHODS}

\section{Study design and patients}

This study was a prospective observational study conducted in consecutive children who presented with chronic abdominal pain at the Department of Pediatrics, Gastroenterology and Nutrition of Children's Hospital in Olsztyn, Poland from January to October 2017. All patients were examined by a pediatric gastroenterologist. In addition, laboratory tests (CRP c-reactive protein, ALT - alanine aminotransferase, AST - aspartate aminotransferase, CBC - complete blood count, ERS - erythrocyte sedimentation rate, serum albumin concentration) and abdominal ultrasounds were performed to exclude an organic cause of abdominal pain. Celiac disease was excluded on the basis of a serological test. Inclusion criteria for enrolment in the present study were: diagnosis of FAP according to Rome III criteria; age 5-12 years; and consent to participate in the study. Patients were excluded from the study if they had organic causes of gastrointestinal tract disorders; presence of another type of FAPD (IBS, FD, AM); known food allergies; other chronic inflammatory gastrointestinal disorders; acute infection; or any antibiotic treatment within the last 8 weeks. Appointments with a dietitian and further measurements were conducted in the Department of Human Nutrition at the Faculty of Food Science (University of Warmia and Mazury in Olsztyn). 
The study protocol was approved by the Bioethics Committee in the Faculty of Medical Sciences at the University of Warmia and Mazury in Olsztyn (Resolution No. 6/2015). Written consent was obtained from all parents or legal guardians of the children after providing explanations of the objectives of the study.

\section{Dietary assessment}

Dietary intake data were collected using a 7-day food diary based on estimated food records over five weekdays (Monday-Friday) and two weekend days (Saturday-Sunday). The children's parents recorded the intake of all foods and beverages in food diary notebooks continuously throughout the day, including meal times. Food weights were estimated using household measures (e.g. small cup, large plate) or portion sizes from packages with standard units. The parents were instructed to record the type and brand name of products whenever possible. If the meal was homemade or if the child was eating out, parents were asked to record as many ingredients as possible and to describe the food preparation and cooking methods (e.g. frying, grilling). The parents received a sample diet record and the study dietitian provided them with instructions on how to complete the diary. Total mean daily energy and selected nutrient intake were calculated based on the Polish table of food composition using "Dieta 5.0" software (The National Food and Nutrition Institute: Warsaw, Poland). The obtained values were then compared to the Human Nutrition Recommendations for the Polish Population, according to each child's age group (4-6 years, 7-9 years, 10-12 years), gender, weight and activity level, and the result was qualified as insufficient, adequate or excessive (Jarosz, 2017).

\section{Gastrointestinal symptoms monitoring}

Over the course of 14 days, and with their parent's help, children completed a daily questionnaire regarding their gastrointestinal symptoms. The frequencies of abdominal pain and stools were recorded as number of events per day. The severity of abdominal pain was assessed using the Wong-Baker FACES Pain Rating Scale (where $0=$ no pain and $10=$ hurts the worst; Garra et al., 2010). Stool consistency was evaluated using the Bristol Stool Form Scale (type 1-2: hard or lumpy stool, type 3-5: normal stool and type 6-7: loose or watery stool; Whelan et al., 2018).

\section{Anthropometrics}

Measurements of body weight $(\mathrm{kg})$ and height $(\mathrm{cm})$ were taken with a precision of $0.1 \mathrm{~kg}$ or $0.1 \mathrm{~cm}$, respectively, using professional devices. Weight was measured with a medical Body Composition Analyzer (SECA mBCA 515, Hamburg, Germany) and height was measured with a stable stadiometer for mobile height measurement (Seca 217, Hamburg, Germany). All measurements were taken in light clothing and without shoes. Body mass index (BMI) was calculated and expressed as BMI z-scores according to reference data for Polish children and adolescents (Kułaga et al., 2010; 2013). BMI was also categorized based on age-sex-specific BMI cut-offs for children according to international standards (International Obesity Task Force, IOTF; Cole and Lobstein, 2012).

\section{Physical activity}

Physical activity at school and during free time was assessed separately. Children could choose one of three answers with parents' help: low, moderate, or high. Physical activity at school was classified as low if most of the time (70\%) was spent in a sitting position, in class or on breaks; moderate if half the time was spent in a sitting position and half the time in motion; and high if most of the time $(70 \%)$ was spent moving or in classes related to high physical exertion. Physical activity during free time was classified as low if most of the time was spent sitting, watching TV, in front of a computer, reading, doing light housework, or on short walks totaling up to $2 \mathrm{~h}$ a week; moderate if walking, cycling, gymnastics, housework or any other light physical activity were performed for $2-3 \mathrm{~h} /$ week; or high if cycling, running or any sport requiring a physical effort were performed for over 3 $\mathrm{h} /$ week. Total physical activity was assessed by combining these two questions regarding physical activity at school and in free time. Respondents were divided into one of the three categories of total physical level: low, moderate, high (Kowalkowska et al., 2018).

\section{Statistical analysis}

Statistical analyses were carried out using STATISTICA software (version 10.0 PL; StatSoft Inc., Tulsa, OK, USA; StatSoft Polska, Kraków, Poland). Categorical variables are presented as percentages (\%) of the sample and continuous variables as medians with 
an interquartile range. Differences between groups were verified with the Kruskal-Wallis test. Before statistical analysis, the normality of all continuous variables was evaluated using a Kolomogorov-Smirnov test. Differences were considered significant for $p<0.05$.

\section{RESULTS}

Twenty-five children between 5 and 11 years of age (mean, $7.9 \pm 2.0$ years) were enrolled in this study; $40 \%$ were female. The average BMI z-score for all patients was $0.41 \pm 1.13$. Nutritional status classification showed that over half of the respondents $(56 \%)$ were characterized by normal weight, and $40 \%$ were

Table 1. Characteristics of study participants

\begin{tabular}{lc}
\hline \multicolumn{1}{c}{ Characteristic } & $\begin{array}{c}\text { All patients } \\
(n=25)\end{array}$ \\
\hline Age, years* & $7.9 \pm 2.0$ \\
Gender, female, $n, \%$ & $10(40)$ \\
BMI z-score* & $0.41 \pm 1.13$ \\
BMI-for-age classification, $n, \%$ & \\
underweight & $1(4)$ \\
normal-weight & $14(56)$ \\
overweight or obese & $10(40)$ \\
Total physical activity, $n, \%$ & \\
low & $9(36)$ \\
moderate & $15(60)$ \\
high & $1(4)$ \\
Physical activity at school, $n, \%$ & \\
low & $8(32)$ \\
moderate & $16(64)$ \\
high & $1(4)$ \\
Physical activity in free-time, $n, \%$ & \\
low & $5(20)$ \\
moderate & $14(56)$ \\
high & $6(24)$ \\
Gastrointestinal symptoms** & \\
abdominal pain intensity, points/day & $1.70(0.79-1.86)$ \\
abdominal pain frequency, times/day & $0.59(0.36-0.79)$ \\
stool consistency, points/day & $3.32(2.75-3.85)$ \\
stool frequency, times/day & $1.01(0.79-1.29)$ \\
\hline
\end{tabular}

*Data are reported as mean $\pm \mathrm{SD}$.

**Data are reported as median (inter-quartile range).

BMI-for-age categorized with sex-specific cut-offs according to the International Obesity Task Force (IOTF) standards (Cole and Lobstein, 2012). overweight or obese, and only one child's BMI indicated being underweight (4\%). Over half of the children declared having moderate physical activity both at school (64\%) and in their free time (56\%). Assessment of gastrointestinal symptoms during two weeks of observation showed that the median abdominal pain intensity was 1.70 (IQR: $0.79-1.86$ ) points/day, with a median frequency of 0.59 (IQR: $0.36-0.79$ ) times/ day. Median stool consistency was 3.32 (IQR: 2.753.85) points/day, with a median frequency of 1.01 (IQR: 0.79-1.29) times/day (Table 1).

The quality assessment of the diet revealed that the energy content was insufficient in $64 \%$ of the children. More than half of the children also consumed insufficient amounts of carbohydrates (80\%), fat (68\%) and fiber (68\%). Moreover, the diet of all the children was characterized by excess intake of protein and in $60 \%$ by excess intake of sugars relative to energy intake (Table 2).

Table 2. Nutritional intake assessment

\begin{tabular}{lc}
\hline \multicolumn{1}{c}{ Characteristic } & $\begin{array}{c}\text { All patients } \\
(n=25)\end{array}$ \\
\hline Energy intake, kcal & \\
excess & $4(16)$ \\
proper & $5(20)$ \\
insufficient & $16(64)$ \\
Carbohydrate intake, g & \\
excess & $3(12)$ \\
proper & $2(8)$ \\
insufficient & $20(80)$ \\
Fat intake, g & \\
excess & $3(12)$ \\
proper & $5(20)$ \\
insufficient & $17(68)$ \\
Protein intake, g & \\
excess & $25(100)$ \\
Fiber intake, g & \\
excess & \\
proper & \\
insufficient & \\
Sugars, \% of energy intake & \\
excess & \\
proper & $17(16)$ \\
\hline
\end{tabular}

Data are reported as $n, \%$. 
Boradyn, K. M., Przybyłowicz, K. E., Jarocka-Cyrta, E. (2020). The role of selected dietary and lifestyle factors in the occurrence of symptoms in children with functional abdominal pain - a pilot study. Acta Sci. Pol. Technol. Aliment., 19(3), 291-300. http://dx.doi. org/10.17306/J.AFS.2020.0833

Analysis of the association between dietary component intake and gastrointestinal symptoms revealed that abdominal pain intensity was significantly higher among children with insufficient intake of fiber (median: 1.75 points/day, IQR 1.18-2.32) than in the group with adequate intake (median: 0.29 points/day, IQR $0.08-0.57 ; p=0.006$ ). There was also a tendency towards a lower frequency of abdominal pain episodes in children with adequate fiber intake, but this difference did not reach statistical significance. There were no significant differences in gastrointestinal symptoms between groups with adequate and inadequate intake of other dietary components (Table 3).

Table 3. Associations between gastrointestinal symptoms and dietary components intake

\begin{tabular}{|c|c|c|c|c|}
\hline \multirow{2}{*}{ Gastrointestinal symptoms } & \multicolumn{3}{|c|}{ Dietary components intake } & \multirow{2}{*}{$p$} \\
\hline & insufficient & adequate & excess & \\
\hline Energy & $n=16$ & $n=5$ & $n=4$ & \\
\hline Abdominal pain intensity, points/day & $1.64(0.71-1.86)$ & $1.71(0.79-2.32)$ & $1.16(0.73-1.45)$ & ns \\
\hline Abdominal pain frequency, times/day & $0.46(0.21-0.79)$ & $0.86(0.36-1.36)$ & $0.43(0.25-0.46)$ & ns \\
\hline Stool consistency, points/day & $3.33(2.33-4.02)$ & $3.59(3.30-3.63)$ & $2.91(2.66-3.27)$ & ns \\
\hline Stool frequency, times/day & $0.93(0.64-1.29)$ & $0.86(0.86-1.00)$ & $0.89(0.46-1.21)$ & ns \\
\hline Carbohydrates & $n=20$ & $n=2$ & $n=3$ & \\
\hline Abdominal pain intensity, points/day & $1.68(0.82-2.29)$ & $0.71(0.14-1.29)$ & $1.04(0.43-1.61)$ & ns \\
\hline Abdominal pain frequency, times/day & $0.57(0.36-0.82)$ & $0.25(0.07-0.43)$ & $0.42(0.07-0.50)$ & ns \\
\hline Stool consistency, points/day & $3.40(2.81-4.04)$ & $2.78(2.56-3.00)$ & $3.07(2.75-3.46)$ & ns \\
\hline Stool frequency, times/day & $0.89(0.79-1.29)$ & $0.82(0.64-1.00)$ & $1.14(0.29-1.29)$ & ns \\
\hline Fat & $n=17$ & $n=5$ & $n=3$ & \\
\hline Abdominal pain intensity, points/day & $1.64(0.71-2.32)$ & $1.00(0.79-1.64)$ & $1.61(1.29-1.71)$ & ns \\
\hline Abdominal pain frequency, times/day & $0.50(0.36-0.79)$ & $0.36(0.21-0.50)$ & $0.42(0.43-0.86)$ & ns \\
\hline Stool consistency, points/day & $3.33(2.50-3.63)$ & $3.30(3.13-4.38)$ & $3.07(2.56-4.50)$ & ns \\
\hline Stool frequency, times/day & $1.29(0.79-1.29)$ & $0.86(0.64-0.86)$ & $0.86(0.64-1.14)$ & ns \\
\hline Sugars & - & $n=10$ & $n=15$ & \\
\hline Abdominal pain intensity, points/day & - & $1.11(0.79-1.64)$ & $1.71(0.71-2.32)$ & ns \\
\hline Abdominal pain frequency, times/day & - & $0.43(0.36-0.64)$ & $0.43(0.21-0.86)$ & ns \\
\hline Stool consistency, points/day & - & $3.38(3.13-4.06)$ & $3.32(2.50-3.85)$ & ns \\
\hline Stool frequency, times/day & - & $0.96(0.86-1.29)$ & $0.86(0.64-1.29)$ & ns \\
\hline Fiber & $n=17$ & $n=4$ & $n=4$ & \\
\hline Abdominal pain intensity, points/day & $1.75(1.18-2.32)^{*}$ & $0.29(0.08-0.57)^{*}$ & $1.16(0.59-1.45)$ & 0.006 \\
\hline Abdominal pain frequency, times/day & $0.64(0.36-0.86)$ & $0.07(0.04-0.43)$ & $0.43(0.25-0.46)$ & ns \\
\hline Stool consistency, points/day & $3.33(2.50-4.02)$ & $3.58(3.04-3.95)$ & $3.04(2.78-3.27)$ & ns \\
\hline Stool frequency, times/day & $0.86(0.79-1.29)$ & $1.29(0.79-1.39)$ & $1.07(0.82-1.21)$ & ns \\
\hline
\end{tabular}

Data are reported as median (inter-quartile range).

*Significance of differences at $p<0.05$ in pairs. 
Boradyn, K. M., Przybyłowicz, K. E., Jarocka-Cyrta, E. (2020). The role of selected dietary and lifestyle factors in the occurrence of symptoms in children with functional abdominal pain - a pilot study. Acta Sci. Pol. Technol. Aliment., 19(3), 291-300. http://dx.doi. org/10.17306/J.AFS.2020.0833

Table 4. Association between gastrointestinal symptoms and non-nutritional lifestyle factors

\begin{tabular}{|c|c|c|c|c|}
\hline \multirow{2}{*}{$\begin{array}{l}\text { Gastrointestinal symptoms } \\
\text { Total physical activity level }\end{array}$} & \multicolumn{3}{|c|}{ Non-nutritional lifestyle factors } & \multirow[t]{2}{*}{$p$} \\
\hline & $\begin{array}{l}\text { low } \\
n=9\end{array}$ & $\begin{array}{c}\text { moderate } \\
n=15\end{array}$ & $\begin{array}{l}\text { high } \\
n=1\end{array}$ & \\
\hline Abdominal pain intensity, points/day & $1.64(0.43-2.25)$ & $1.61(0.86-1.86)$ & $0.36(0.36-0.36)$ & ns \\
\hline Abdominal pain frequency, times/day & $0.43(0.07-0.79)$ & $0.50(0.36-0.79)$ & $0.07(0.07-0.07)$ & ns \\
\hline Stool consistency, points/day & $3.32(2.75-4.38)$ & $3.30(2.56-3.63)$ & $3.33(3.33-3.33)$ & ns \\
\hline Stool frequency, times/day & $0.86(0.64-1.00)$ & $0.93(0.79-1.29)$ & $1.43(1.43-1.43)$ & ns \\
\hline Physical activity level at school & $\begin{array}{c}\text { low } \\
n=8\end{array}$ & $\begin{array}{c}\text { moderate } \\
n=16\end{array}$ & $\begin{array}{l}\text { high } \\
n=1\end{array}$ & \\
\hline Abdominal pain intensity, points/day & $1.32(0.29-1.68)$ & $1.68(0.95-2.29)$ & $0.36(0.36-0.36)$ & ns \\
\hline Abdominal pain frequency, times/day & $0.29(0.07-0.61)$ & $0.57(0.39-1.04)$ & $0.07(0.07-0.07)$ & ns \\
\hline Stool consistency, points/day & $3.74(3.16-4.44)$ & $3.13(2.42-3.61)$ & $3.33(3.33-3.33)$ & ns \\
\hline Stool frequency, times/day & $0.93(0.75-1.29)$ & $0.89(0.71-1.29)$ & $1.43(1.43-1.43)$ & ns \\
\hline Physical activity in free-time & $\begin{array}{l}\text { low } \\
n=5\end{array}$ & $\begin{array}{c}\text { moderate } \\
n=14\end{array}$ & $\begin{array}{l}\text { high } \\
n=6\end{array}$ & \\
\hline Abdominal pain intensity, points/day & $2.25(1.00-2.93)$ & $1.45(0.79-1.75)$ & $1.25(0.36-3.07)$ & ns \\
\hline Abdominal pain frequency, times/day & $0.43(0.21-0.79)$ & $0.50(0.36-0.79)$ & $0.36(0.07-1.36)$ & ns \\
\hline Stool consistency, points/day & $3.00(2.19-4.02)$ & $3.21(2.56-3.63)$ & $3.53(3.33-4.06)$ & ns \\
\hline Stool frequency, times/day & $0.86(0.79-1.00)$ & $0.86(0.64-1.14)^{*}$ & $1.36(1.29-1.50)^{*}$ & 0.031 \\
\hline BMI categories & $\begin{array}{c}\text { underweight } \\
n=1\end{array}$ & $\begin{array}{c}\text { normal-weight } \\
n=14\end{array}$ & $\begin{array}{c}\text { overweight } \\
n=10\end{array}$ & \\
\hline Abdominal pain intensity, points/day & $1.86(1.86-1.86)$ & $1.23(0.71-1.71)$ & $1.75(0.86-3.07)$ & ns \\
\hline Abdominal pain frequency, times/day & $0.36(0.36-0.36)$ & $0.50(0.36-0.79)$ & $0.39(0.21-1.29)$ & ns \\
\hline Stool consistency, points/day & $2.50(2.50-2.50)$ & $3.33(3.07-3.85)$ & $3.29(2.75-4.02)$ & ns \\
\hline Stool frequency, times/day & $0.43(0.43-0.43)$ & $0.89(0.79-1.29)$ & $0.96(0.79-1.29)$ & ns \\
\hline
\end{tabular}

Data are reported as median (inter-quartile range).

*Significance of differences at $p<0.05$ in pairs.

The association between non-nutritional lifestyle factors, physical activity level or BMI categories, and gastrointestinal symptoms is shown in Table 4. Stool frequency was significantly lower in children who reported moderate physical activity in their free-time (median: 0.86 times/day, IQR 0.64-1.14) than in children with high free time physical activity (median: 1.36 times/day, IQR: $1.29-1.50 ; p=0.031$ ). There were no significant differences in other gastrointestinal symptoms between groups with various levels of total physical activity, at school or in their free time. The analysis of gastrointestinal symptoms stratified by BMI showed that there were no significant differences in the intensity and frequency of abdominal pain, or in the consistency and frequency of stools, between children in those BMI categories. However, there was a tendency towards lower abdominal pain intensity in the group with normal-weight than in the overweight or underweight children. 


\section{DISCUSSION}

This is one of the first studies focusing on lifestyle factors, such as physical activity level, dietary intake and BMI in a group of children with FAP. Most studies available to date have focused on mixed groups including patients with various types of FAPDs, or on patients with IBS only. In 2016, Rome IV criteria introduced the new term "FAP-NOS" (functional abdominal pain - not otherwise specified) to standardize the nomenclature used in research and to prevent confusion in interpreting study results (Hyams et al., 2016). Due to the date when the methodology of this project was prepared, our study used terminology based on Rome III criteria (Rasquin et al., 2006). Nevertheless, the diagnostic criteria of FAP-NOS in the Rome IV classification are strictly identical to the 2006 version (Hyams et al., 2016).

One of the most important factors which may be related to the occurrence of FAPD symptoms is a balanced diet. In the conducted study, excessive protein intake was observed in all patients. Previous studies suggest that both the amount and the type of consumed protein may be related to symptoms of FAPDs. One of the triggering factors are products of protein fermentation in the colon, like gas such as hydrogen sulfide or phenols. In addition, certain types of protein, such as gluten or cow's milk protein, can exacerbate symptoms in people with FAPDs (Gibson et al., 2013; Llanos-Chea and Fasano, 2018; Pensabene et al., 2018). At the same time, insufficient energy content, carbohydrate, and fat intake were reported in the diet of more than half of the patients in our study. This could be partly due to an inaccurate diet record, which is the method considered to be the gold standard for collecting information about routinely consumed portions and types of food, and the dietary habits of patients. However, parents often do not know what children eat at school or when they are with friends. In addition, children sometimes do not want to admit to eating sweets and unhealthy snacks (Foster and Bradley, 2018; Ortega et al., 2015). The eating out habits of children with FAPDs are especially important due to the potential worsening of gastrointestinal symptoms. Shau et al. (2016) and Chouliaras et al. (2019) observed that increased consumption of junk food and foods high in fat, trans fatty acids, sugar and sodium may be associated with exacerbation of disease symptoms. This main limitation of the food diary method is usually mentioned in literature and may be present in this research (Foster and Bradley, 2018; Ortega et al., 2015). Nevertheless, it is important to investigate the reasons for potential insufficient energy and macronutrient intake in children, as both inadequate and excessive intake of some nutrients can determine an increased intensity or frequency of gastrointestinal symptoms (Chumpitazi, 2018; Gupta et al., 2018; Rajindrajith et al., 2018).

Special attention was paid in this study to carbohydrates in general, and to fiber and sugars. In recent years, studies have focused on the amount of carbohydrates and sugars in the diet of patients with FAPDs. Increased sugar content in the diet, as well as the intolerance to short-chain poorly absorbed sugars may play a significant role in exacerbating the symptoms of the disease (Chumpitazi 2018; Chumpitazi and Shulman, 2016; Gibson et al., 2013). Our results did not show a relationship between the intake of these macronutrients and gastrointestinal symptoms. However, we noted that adequate fiber intake was associated with significantly lower abdominal pain intensity compared to inadequate intake among children with FAP. A randomized, double-blind study conducted by Romano et al. (2013) demonstrated similar results. In this study, conducted among children with chronic abdominal pain or IBS, severity of symptoms was significantly reduced in the group which received a special type of dietary fiber as compared to the control group receiving a placebo (Romano et al., 2013). Feldman et al. (1985) also reported an improvement in abdominal pain frequency in children with recurrent abdominal pain (RAP) after corn fiber supplementation. Our results also share a number of similarities with Paulo et al.'s (2006) findings, which suggest that inadequate daily fiber intake may be a triggering factor for RAP. Conversely, other research did not confirm significant improvements in gastrointestinal symptoms following treatment with dietary fiber supplementation in children with FAPDs (Horvath et al., 2012; Rutten et al., 2015). These discrepant results indicate that the relationship between fiber intake and FAPDs is still controversial. For many years, higher intake of fiber was recommended not only in children with FAPDs, but also in other functional gastrointestinal disorders (FGIDs), mainly constipation. However, in 2014 the 
Boradyn, K. M., Przybyłowicz, K. E., Jarocka-Cyrta, E. (2020). The role of selected dietary and lifestyle factors in the occurrence of symptoms in children with functional abdominal pain - a pilot study. Acta Sci. Pol. Technol. Aliment., 19(3), 291-300. http://dx.doi. org/10.17306/J.AFS.2020.0833

North American Society for Pediatric Gastroenterology, Hepatology, and Nutrition (NASPGHAN) and the European Society of Pediatric Gastroenterology, Hepatology, and Nutrition (ESPGHAN) published guidelines which do not support the use of fiber supplements as a treatment for constipation (Tabbers et al., 2014). Additional studies in precisely diagnosed patients are therefore required to determine whether an adequate fiber intake is sufficient to prevent gastrointestinal symptoms and whether fiber supplementation may be necessary.

A further lifestyle factor which may potentially determine the intensity and frequency of gastrointestinal symptoms, in addition to diet, is the level of physical activity (Hajizadeh et al., 2018). In the current study, we found a significant association between physical activity and stool frequency in children with FAP. Patients characterized by high physical activity levels in their free time declared higher stool frequencies than the group with moderate physical activity. Similar results were observed in a study conducted by Seidenfaden et al. (2018) in children with constipation, in which patients without symptoms were found to exercise significantly more often than the group with constipation. A study by Asakura et al. (2017) also revealed that a high physical activity level was associated with lower incidences of constipation among children. These results support the theory that physical activity may improve colon motility and reduce the risk of constipation (Gao et al., 2019; Seidenfaden et al., 2018). In addition, exercising may decrease stress and improve mental health, which can be associated with the occurrence of gastrointestinal symptoms (Hosseinzadeh et al., 2011; Phatak and Pashankar, 2014). However, further studies are needed to determine whether the form and intensity of physical activity play a role and if so, which type of activity is the most effective in children with FAP.

Physical activity may also influence gastrointestinal symptoms indirectly, by preventing people from becoming overweight or obese (Phatak and Pashankar, 2014). In the last few years, research has suggested that excessive body weight may have an impact on the occurrence of symptoms in children with FAPDs (Bonilla et al., 2011; Phatak and Pashankar, 2014; Teitelbaum et al., 2009). In a prospective cohort study of the pediatric population with FAP, IBS and FD, Bonilla et al. (2011) showed a higher intensity and frequency of pain in obese patients. Phatak and Pashankar (2014) also reported that obese or overweight children were at an increased risk of at least one of the FGIDs, compared to children with normal weight. No clear association was observed between overweight subjects and FAP in particular, but this could be due to the small number of patients with FAP in the study population. However, the authors did note an association between overweight and functional abdominal pain syndrome (FAPS) (Phatak and Pashankar, 2014). Our study did not find a significant association between BMI and abdominal pain. Nevertheless, there was a tendency towards lower intensity of abdominal pain in children with normal weight compared to underweight or overweight children. One explanation of this relationship may be the eating habits of obese children, such as a greater tendency to overeating or choosing high fructose products (Bonilla et al., 2011; Pawłowska et al., 2018). Improper diet increases the risk of nutrition deficiencies or excessive sugar intake and, in consequence, may aggravate symptoms.

The main limitation of this pilot study is the small sample size, and it is possible that some associations may not have achieved statistical significance. In addition, this association study does not allow the authors to affirm the causality of the observed relationships. Nevertheless, to the best of our knowledge, this is the first study to examine associations between multiple lifestyle factors and symptoms of FAP in children. There are several strengths in this study. First, implementing a 7-day food diary allowed us to conduct a thorough dietary assessment, reflecting variability in eating behaviors throughout the week. Another strength of this study lies in the carefully selected study sample, as the main enrolment criterion was a diagnosis of FAP made by an expert gastroenterologist after careful examination of each case and excluding differential diagnoses.

The results of this pilot study can provide relevant information for the prevention and treatment of gastrointestinal symptoms in children with FAP. Our findings suggest that simple recommendations relative to modifiable lifestyle factors, such as diet or physical activity, may help reduce abdominal pain intensity and improve stool frequency, as part of treatment. Moreover, these results support promoting physical activity and healthy eating habits in children with FAP, and 
Boradyn, K. M., Przybyłowicz, K. E., Jarocka-Cyrta, E. (2020). The role of selected dietary and lifestyle factors in the occurrence of symptoms in children with functional abdominal pain - a pilot study. Acta Sci. Pol. Technol. Aliment., 19(3), 291-300. http://dx.doi. org/10.17306/J.AFS.2020.0833

could potentially be applicable to other patient groups and even to healthy children. Nevertheless, future prospective randomized control trials examining the influence of these factors on the severity and frequency of symptoms in children with FAP are needed to confirm these findings.

\section{ACKNOWLEDGEMENTS}

We thank Dr. Joanna Cyrta for her assistance in preparing the manuscript.

\section{REFERENCES}

Asakura, K., Masayasu, S., Sasaki, S. (2017). Dietary intake, physical activity, and time management are associated with constipation in preschool children in Japan. Asia Pac. J. Clin. Nutr., 26(1), 118-129.

Bonilla, S., Wang, D., Saps, M. (2011). Obesity predicts persistence of pain in children with functional gastrointestinal disorders. Int. J. Obes. (Lond)., 35(4), 517-521. https://doi.org/10.1038/ijo.2010.245

Brusaferro, A., Farinelli, E., Zenzeri, L., Cozzali, R., Esposito, S. (2018). The management of paediatric functional abdominal pain disorders: Latest evidence. Pediatr. Drugs, 20, 235-247. https://doi.org/10.1007/s40272-018-0287-z

Chouliaras, G., Kondyli, C., Bouzios, I., Spyropoulos, N., Chrousos, G. P., Roma-Giannikou, E. (2019). Dietary habits and abdominal pain-related functional gastrointestinal disorders: A school-based, cross-sectional analysis in Greek children and adolescents. J. Neurogastroenterol. Motil., 25(1), 113-122. https://doi.org/10.5056/ jnm17113

Chumpitazi, B. P. (2018). Update on dietary management of childhood functional abdominal pain disorders. Gastroenterol. Clin. North. Am., 47, 715-726. https://doi. org/10.1016/j.gtc.2018.07.001

Chumpitazi, B. P., Shulman, R. J. (2016). Dietary carbohydrates and childhood functional abdominal pain. Ann. Nutr. Metab., 68(Suppl. 1), 8-17. https://doi. org/10.1159/000445390

Cole, T. J., Lobstein, T. (2012). Extended international (IOTF) body mass index cut-offs for thinness, overweight and obesity. Pediatr. Obes., 7(4), 284-294. https://doi.org/10.1111/j.2047-6310.2012.00064.x

Feldman, W., McGrath, P., Hodgson, C., Ritter, H., Shipman, R. T. (1985). The use of dietary fiber in the management of simple, childhood, idiopathic, recurrent, abdominal pain. Results in a prospective, double-blind, randomized, controlled trial. Am. J. Dis. Child., 139, 1216-1218. https://doi.org/10.1001/archpedi.1985.02140140050025

Foster, E., Bradley, J. (2018). Methodological considerations and future insights for 24-hour dietary recall assessment in children. Nutr. Res., 51, 1-11. https://doi. org/10.1016/j.nutres.2017.11.001

Gao, R., Tao, Y., Zhou, C., Li, J., Wang, X., Chen, L., ..., Guo, L. (2019). Exercise therapy in patients with constipation: a systematic review and meta-analysis of randomized controlled trials. Scand. J. Gastroenterol., 54(2), 169177. https://doi.org/10.1080/00365521.2019.1568544

Garra, G., Singer, A. J., Taira, B. R., Chohan, J., Cardoz, H., Chisena, E., Thode, H. C. (2010). Validation of the Wong-Baker FACES Pain Rating Scale in pediatric emergency department patients. Acad. Emerg. Med., 17, 50-54. https://doi.org/10.1111/j.1553-2712.2009.00620.x

Gibson, P. R., Barrett, J. S., Muir, J. G. (2013). Functional bowel symptoms and diet. Intern. Med. J., 43(10), $1067-$ 74. https://doi.org/10.1111/imj.12266

Gupta, S., Schaffer, G., Saps, M. (2018). Pediatric irritable bowel syndrome and other functional abdominal pain disorders: an update of non-pharmacological treatments. Expert. Rev. Gastroenterol. Hepatol., 12(5), 447-456. https://doi.org/10.1080/17474124.2018.1462699

Hajizadeh M. B., Tartibian, B., Mooren, F. C., FitzGerald, L. Z., Kruger, K., Chehrazi, M., Malandish, A. (2018). Low-to-moderate intensity aerobic exercise training modulates irritable bowel syndrome through antioxidative and inflammatory mechanisms in women: Results of a randomized controlled trial. Cytokine, 102, 18-25. https://doi.org/10.1016/j.cyto.2017.12.016

Horvath, A., Dziechciarz, P., Szajewska, H. (2012). Systematic review of randomized controlled trials: fiber supplements for abdominal painrelated functional gastrointestinal disorders in childhood. Ann. Nutr. Metab., 61(2), 95-101. https://doi.org/10.1159/000338965

Hosseinzadeh, S. T., Poorsaadati, S., Radkani, B., Forootan, M. (2011). Psychological disorders in patients with chronic constipation. Gastroenterol. Hepatol. Bed. Bench., 4, 159-163.

Hyams, J. S., Di Lorenzo, C., Saps, M., Shulman, R. J., Staiano, A., van Tilburg, M. (2016). Childhood functional disorders: child and adolescents. Gastroenterology, 150, 1456-1468. https://doi.org/10.1053/j. gastro.2016.02.015

Jarosz, M. (2017). Normy żywienia dla populacji polskiej - nowelizacja [Human nutrition recommendations for Polish population]. Warsaw, Poland: IZZ [in Polish].

Kowalkowska, J., Wadolowska, L., Czarnocinska, J., Czlapka-Matyasik, M., Galinski, G., Jezewska-Zychowicz, 
Boradyn, K. M., Przybyłowicz, K. E., Jarocka-Cyrta, E. (2020). The role of selected dietary and lifestyle factors in the occurrence of symptoms in children with functional abdominal pain - a pilot study. Acta Sci. Pol. Technol. Aliment., 19(3), 291-300. http://dx.doi. org/10.17306/J.AFS.2020.0833

M., ..., Wyka, J. (2018). Reproducibility of a Questionnaire for Dietary Habits, Lifestyle and Nutrition Knowledge Assessment (KomPAN) in Polish Adolescents and Adults. Nutrients, 10(12). https://doi.org/10.3390/ nu10121845

Kułaga, Z., Różdżyńska,A., Palczewska, I., Grajda,A., Gurzkowska, B., Napieralska, E. (2010) Percentile charts of height, body mass and body mass index in children and adolescents in Poland - results of the OLAF study. Stand. Med., 7, 690-700.

Kułaga, Z., Grajda, A., Gurzkowska, B., Góźdź, M., Wojtyło, M., Swiąder, A., ..., Litwin, M. (2013). Polish 2012 growth references for preschool children. Eur. J. Pediatr., 172(6), 753-761. https://dx.doi. org/10.1007\%2Fs00431-013-1954-2

Landry, B. W., Fischer, P. R., Driscoll, S. W., Koch, K. M., Harbeck-Weber, C., Mack, K. J., ..., Brandenburg, J. E. (2015). Managing chronic pain in children and adolescents: A clinical review. PMR, 7(11S), S295-S315. https://doi.org/10.1016/j.pmrj.2015.09.006

Llanos-Chea, A., Fasano, A. (2018). Gluten and functional abdominal pain disorders in children. Nutrients, 10(10), 1491. https://doi.org/10.3390/nu10101491

Nurko, S. (2009). The tip of the iceberg: the prevalence of functional gastrointestinal diseases in children. $\mathrm{J}$. Pediatr., 154(3), 313-315. https://doi.org/10.1016/j. jpeds.2008.11.012

Ortega, R. M., Pérez-Rodrigo, C., López-Sobaler, A. M. (2015). Dietary assessment methods: dietary records. Nutr. Hosp., 31(3), 38-45. https://doi.org/10.3305/ nh.2015.31.sup3.8749

Paulo, A. Z., Amancio, O. M., de Morais, M. B., Tabacow, K. M. (2006). Low-dietary fiber intake as a risk factor for recurrent abdominal pain in children. Eur. J. Clin. Nutr., 60(7), 823-827. https://doi.org/10.1038/sj.ejcn.1602386

Pawłowska, K., Umławska, W., Iwańczak, B. (2018). A link between nutritional and growth states in pediatric patients with functional gastrointestinal disorders. J. Pediatr., 199, 171-177. https://doi.org/10.1016/j. jpeds.2018.02.069

Pensabene, L., Salvatore, S., D’Auria, E., Parisi, F., Concolino, D., Borrelli, O., ..., Saps, M. (2018). Cow's milk protein allergy in infancy: A risk factor for functional gastrointestinal disorders in children? Nutrients, 10(11), 1716. https://dx.doi.org/10.3390\%2Fnu10111716

Phatak, U. P., Pashankar, D. S. (2014). Prevalence of functional gastrointestinal disorders in obese and overweight children. Int. J. Obes. (Lond), 38(10), 1324-27. https:// doi.org/10.1038/ijo.2014.67

Rasquin, A., Di Lorenzo, C., Forbes, D., Guiraldes, E., Hyams, J. S., Staiano, A., Walker, L. S. (2006). Childhood functional gastrointestinal disorders: child/adolescent. Gastroenterology, 130, 1527-37. https://doi. org/10.1053/j.gastro.2005.08.063

Rajindrajith, S., Zeevenhooven, J., Devanarayana, N. M., Perera, B. J. C., Benninga, M. A. (2018). Functional abdominal pain disorders in children. Exp. Rev. Gastroenterol. Hepatol., 12(4), 369-390. https://doi.org/10.1080/ 17474124.2018.1438188

Romano, C., Comito, D., Famiani, A., Calamarà, S., Loddo, I. (2013). Partially hydrolyzed guar gum in pediatric functional abdominal pain. World J. Gastroenterol., 19(2), 235-240. https://doi.org/10.3748/wjg.v19.i2.235

Rutten, J. M., Korterink, J. J., Venmans, L. M., Benninga, M. A., Tabbers, M. M. (2015). Nonpharmacologic treatment of functional abdominal pain disorders: a systematic review. Pediatrics, 135(3), 522-535. https://doi. org/10.1542/peds.2014-2123

Seidenfaden, S., Ormarsson, O. T., Lund, S. H., Bjornsson, E. S. (2018). Physical activity may decrease the likelihood of children developing constipation. Acta Paediatr., 107(1), 151-155. https://doi.org/10.1111/apa.14067

Shau, J. P., Chen, P. H., Chan, C. F., Hsu, Y. C., Wu, T. C., James, F.E., Pan, W. H. (2016). Fast foods - are they a risk factor for functional gastrointestinal disorders? Asia Pacific J. Clin. Nutr., 25(2), 393-401. https://doi. org/10.6133/apjen.2016.25.2.28

Tabbers, M. M., DiLorenzo, C., Berger, Y. M., Faure, C., Langendam, W. M., Nurko, S., ..., Benninga, M. A. (2014). Evaluation and treatment of functional constipation in infants and children: Evidence-based recommendations from ESPGHAN and NASPGHAN. J. Pediatr. Gastroenterol. Nutr., 58(2), 258-274.

Teitelbaum, J., Sinha, P., Micale, M., Yeung, S., Jaeger, J. (2009). Obesity is related to multiple functional abdominal diseases. J. Pediatr., 154(3), 444-446. https://doi. org/10.1016/j.jpeds.2008.09.053

Whelan, K., Martin, L. D., Staudacher, H. M., Lomer, M. C. E. (2018). The low FODMAP diet in the management of irritable bowel syndrome: an evidence-based review of FODMAP restriction, reintroduction and personalisation in clinical practice. J. Hum. Nutr. Diet., 31, 239-255. https://doi.org/10.1111/jhn. 12530 